\title{
The Reproductive Performance of the Nigerian Dwarf Sheep
}

\author{
by \\ B. I. Onjt, J. Steinba ch, E. A. Olalokt, and I. O. A. Adeleye;
Department of Animal Science, Unizersity of Ibadan.

\section{SUMMARY} \\ dam number and sire number. The \\ animals were allowed to breed all the \\ year round.
}

THREE of the most important parameters of reproduction in sheep, the age at first lam. bing, the lambing interval and the number of lambs born per ewe at each lambing, were analysed from the herdbook of the breeding flock of the University of Ibadan for the period-1968 to 974 . The means were as follows :

I. age at first lambing: $\quad 424.9 \quad(310-692)$

2. lambing interval: $\quad 234.4\left(5^{I}-57 x\right)$

3. number of lembs at birth $\mathrm{I} \cdot 4(\mathrm{I}-3)$

Of the 663 lambings, recorded, $3^{8}$ percent resulted in twins and 4 percent in triplets. The percentage of multiple births increased with the number of lambings an ewe had completed. The wide ranges in performance indicate that there is scope for improvement indicate that there is scope for improvernent of sheep through improved management and or through selection.

\section{INTRODUGTION}

Very little attention has in the past been paid to the study of the biology of reproduction of the Nigerian Dwarf sheep. Earlier attempts on this (Hill I960, Dettmers and Loosli 1974) have been confined to the gross picture of their reproductive performance. Efforts have therefore been made in this paper to cxamine in greater details three of the most important parameters of reproduction in the Nigerian Dwarf Sheep-the age at first lambing, the interval between lambings and the performance at lambings.

\section{MATERIALS AND METHODS}

The raw material for this study came from the herd book of the breeding flock at the University of Ibadan Farm. The period covered extend from Ig68 to I 974 . 'The records were kept by the herdsmen and the parameters recorded include flock number, birth weight, sex, type of birth,

\section{Age at first lambing}

The age was calculated from the day of birth to the day prior to the date of the frrst lambing. For this parameter a total of 70 ewes born between 1972 and 1973 were used in the calculation, the choice of period depending entirely on the accuracy of the information recorded. The means and distribution of the age at first lambing were determined and an analysis of variance was done to determine the effect of season of birth on the age at first lambing.

\section{Interval between lambings}

This interval was calculated from the day of one lambing to the day prior to the date of the next lambing. A total of 4.57 births from 122 ewes spread over the period of 7 years - ig68 to 1974-was analysed to determine the mean, the distribution and the effect of the stage of lambing on the interval. The number of lambings per ewe ranged from 2 to Io. The repeatability of the lambing interval using the analysis of variance method (Turner \& Young 1969) was estimated.

\section{Performance at lambing}

The number and sex of the lambs born per ewe at lambing were determined from 663 lambings recorded between January $197 \mathrm{I}$ and December 1974 . Monthly and yearly effects were calculated using the analysis of variance. The pattern of incidence of multiple births was also checked. Estimates of the repeatability of the number of lambs born per ewe using two methods - analysis of variance method and the regression method werc calculated. 
RESULTS AND DISCUSSION

\section{Age at first Lambing}

The mean age at first lambing obtained for the flock was $424 \cdot 9=20$ lays, range $310=696$ days. The summary of the distribution of the age at various intervals is illustrated in figure I. About $78.6 \%$ of all the ewes had their first lambing before the age of 500 days ( 16 months approx.) at a mean agc of $406 \cdot 9 \div 11 \cdot 5$ days, range $35^{0}-494$ days. This therefore suggests that the normal age at first lambing for the Nigerian Dwarf sheep would be in this range. The ewes born in the dry scason (October-March) had their first lambs at a significantly younger age (395.5 days) than those born in the wet season ( 443 days). This is not surprising since the former group had to go through the dry season still suckling and weaned when pastures become easily available the following wet season. This therefore suggests that there may be room for improvement in the flock performance through improvement in the environment of the flock. Indeed Orji and Steinbach (1976) werc able to reduce the age at puberty in the Nigerian Dwarf cwe through supplemental feeding.

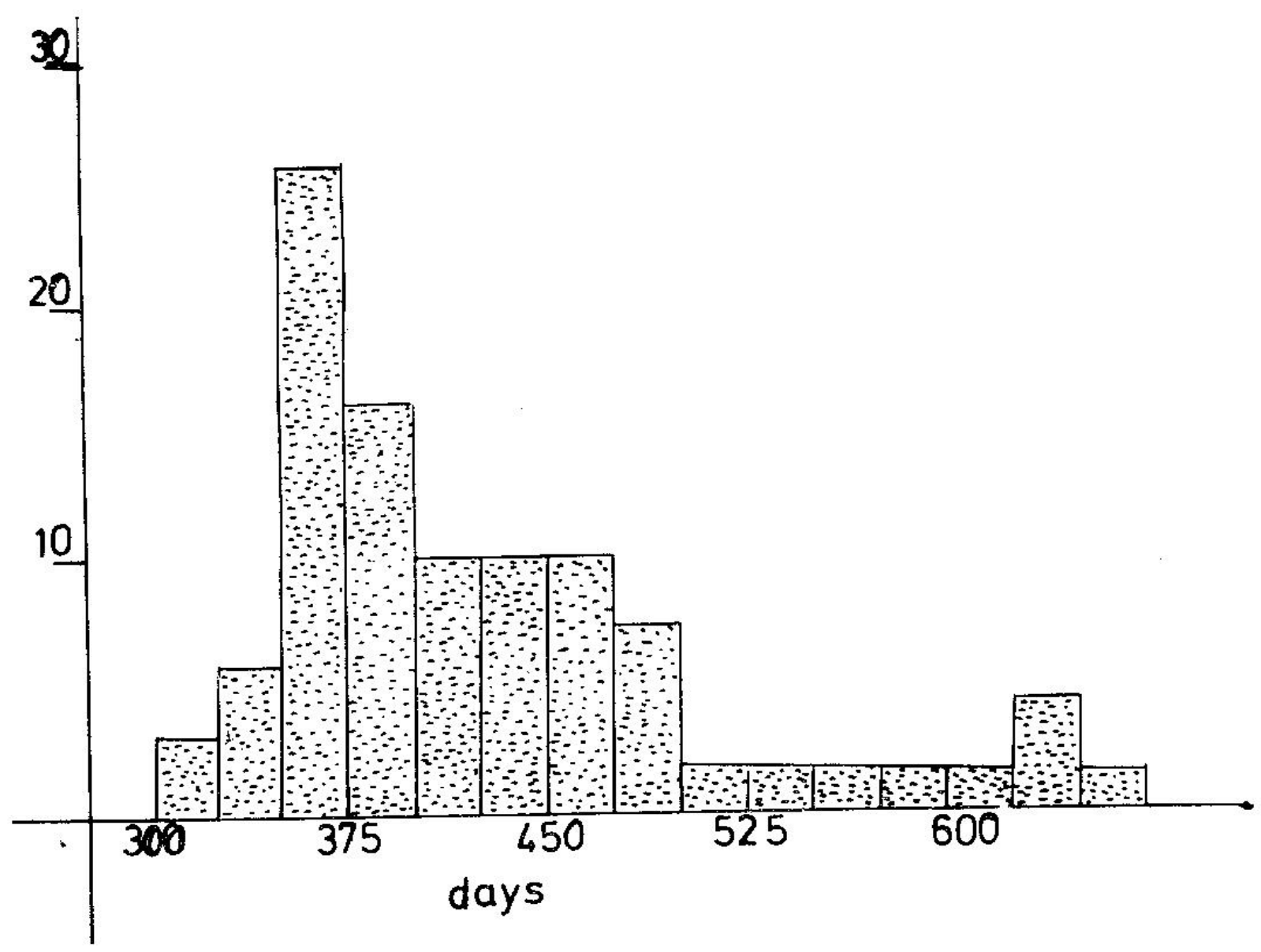

Figure I : Frequency Distribution of the age at first Lambing 


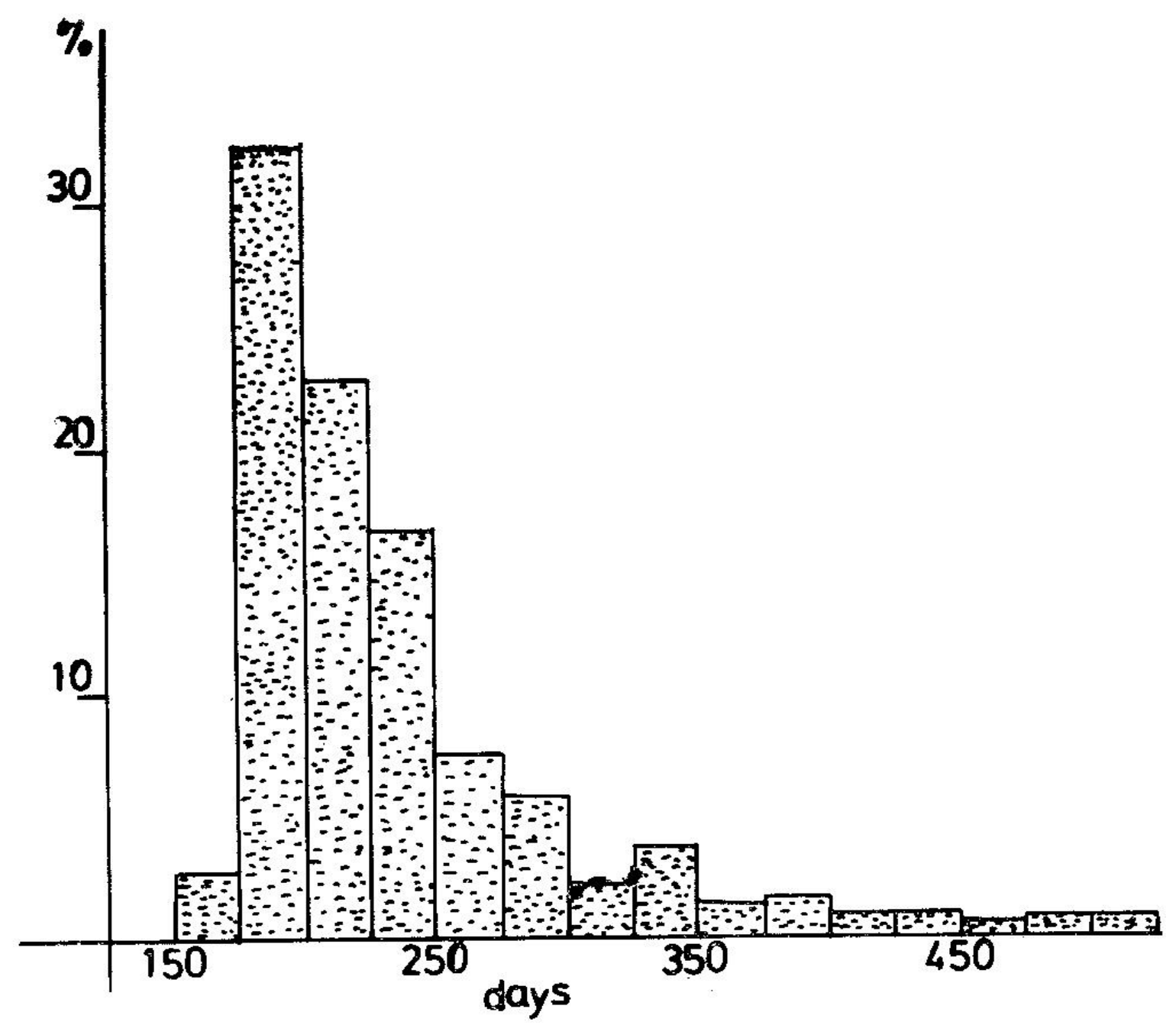

Figure 2: Frequency Distribution of the Lambing interval

\section{Interval between lambings}

The summary of the distribution of the lambing is illustrated in figure 2. The overall mean of the lambing intcrval was $234 \cdot 4-6.8$ days, range $55 \mathrm{I}-57 \mathrm{I}$ days. This mean value is within the range of values obtained for the other Nigcrian breeds of sheep-276 and $27^{\circ}$ days for the Yankassa and Ouda breeds respectively (Ferguson $\mathrm{r}^{6} 64$ ). However because 86 percent of all the lambing intervals lie between I $75-300$ days at a mean of $216 \cdot 78 \pm 3.5$ days, it would be probably safe to assume that this is the normal value for the lambing interval of this breecl. This would therefore mean that the Nigerian Dwarf sheep in this environment has a shorter lambing. interval than the other Nigerian brecds. The interval between lambings decreased with the number of lambings completed $(\mathrm{r}=0.45 \mathrm{P}<0.05)$. The mean decreased from 232 days between the first and second lambings to 208 days between the fourth and fifth lambings. This reduction with lambings is in agreement with the overall improvement in the efficiency of the reproductive performance of sheep with successive lambings, observed by several workers (Terrill r968, Asdcll r 964, Yalcin \& Bichard $\times 964)$. The repeatability value for the lambing interval is 0.036 . This is low and therefore suggests that the expected gain by selection for shorter lambing interval would be small. 


\section{The performance at lambings}

The overall mean of the number of lambs born per lambing completed in the flock was $I \cdot 46 \pm 0 \cdot 04$ lambs, range I-3 lambs. Differences in lambing performance (expressed as lambs born per lambing) between the months and between the years were not significant ( $\mathrm{P}<0.05 \mathrm{~F}$-test). It could therefore be seen that apart from lambing all through the year, there are no significant differences in the performance at lambings of the Nigerian Dwarf sheep from one part of the year to the other.

The lamb crop per lambing completed varied with the stage of lambing. This is illustrated in figure 3 . There is a positive and a highly significant correlation between the stage of lambing and the lamb crop per lambing $(R=0.8 \mathrm{I})$. The equation of the lamb crop (Y) per lambing on the stage of lambing(X) is $\left(Y=-1 \cdot 09^{-1}\right.$ $\left.0 \cdot 18 \mathrm{X}-0 \cdot 0098 \mathrm{X}^{2}\right)$. The 123.7 mean lambing percentage obtained for the first lambing though below the overall mean for all lambings, agrees with the value obtained for early breeding in some other

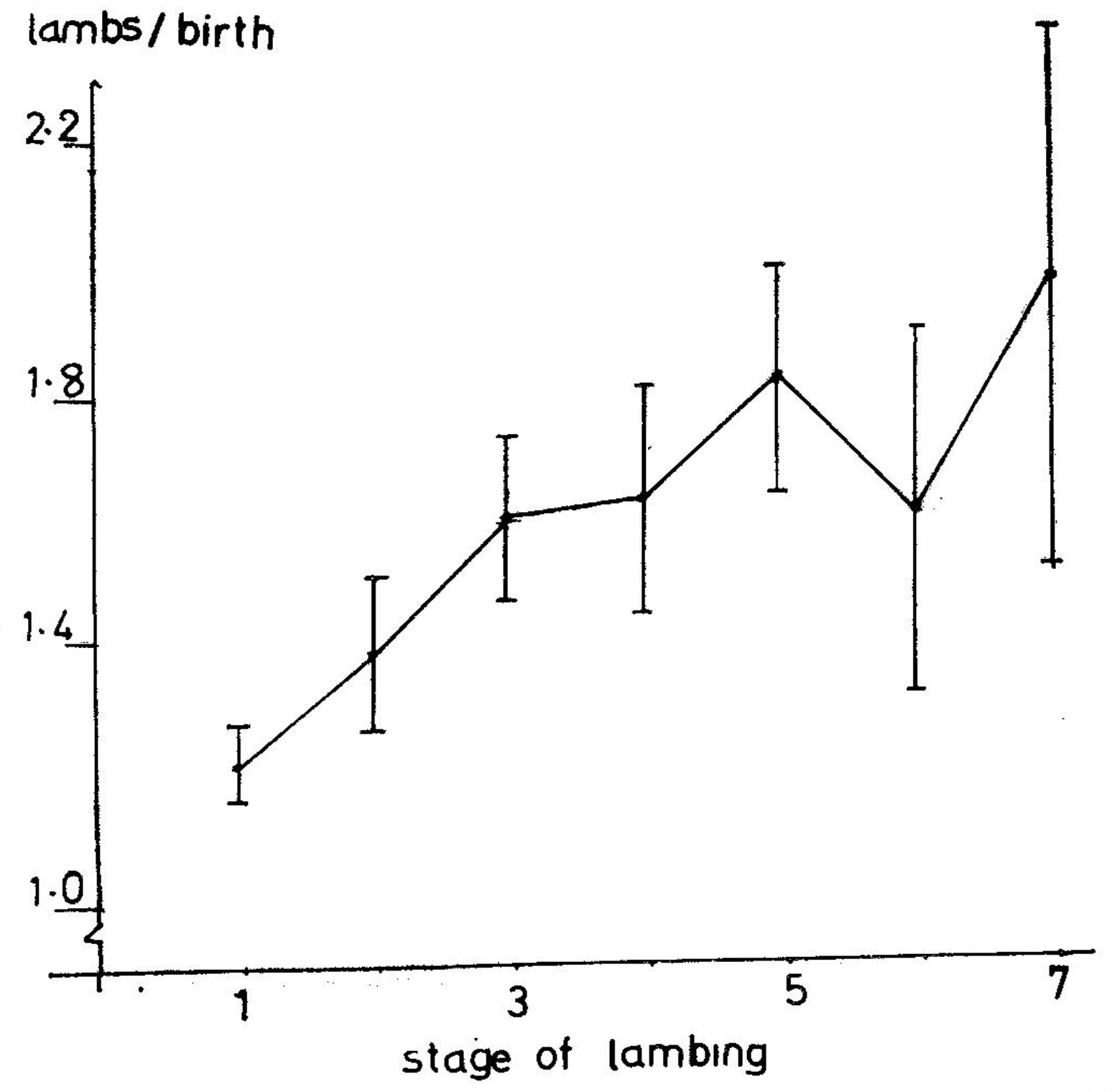

Figure 3 : The effect of the stage of lambing on the performance at Lambing 


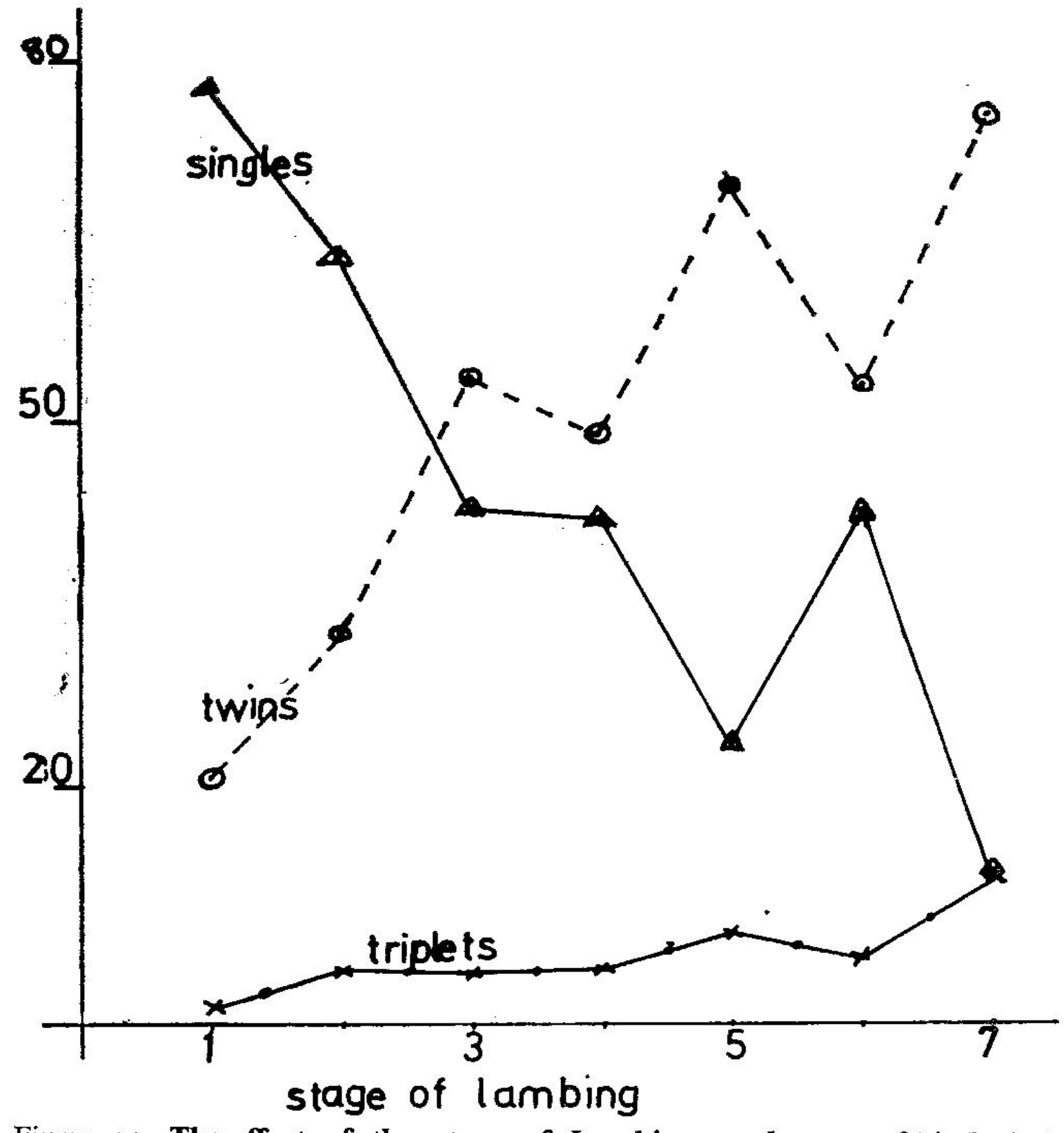

Figure 4: The effect of the stage of Lambing on the type of birth ( $\%$ )

breeds of sheep - (100-1 $24 \%$ for Iceland sheep, Dyrmundsson 1969; I00\% for the Scottish Blackface $X$ Merino, Donald et al 1968; 128\% for Border Leicester X Cheviot, Yalcin and Bichard 1964 ). $41 \cdot 9 \%$ of all the lambings were multiple births while $58.1 \%$ were singles. Of the multiple births, $90.7 \%$ were twins and $9.3 \%$ triplets. Small and non-significant monthly differences exist in the ratio of multiple/single lambs born per lambing. The overall percentage of twin births increased with lambings, that of singles declined. There were only slight increases in triplet births as lambing progressed (figure 4). By comparing these results with figures available for other Nigerian breeds of sheep we are inclined to conclude that the Nigerian Dwarf sheep is highly prolific. The mean of $4 \times \cdot 9 \%$ for multiple births increasing to $87 \%$ by the $7^{\text {th }}$ lambing is much higher than $25.5 \%$ and I $4.08 \%$ reported by Ferguson (1964) for the Yankassa and Ouda breeds respec- 
lively. These figures compare favourably with $49.1 \%, 46.6 \%, 49.1 \%$ and $51.0 \%$ for Cheviot, Shropshire, Landrace and Oxford Down breeds respectively (Rendel 1956 ) and $63 \%$ for the Blackface sheep (Jones 1959). There is a positive and a highly significant correlation between the stage of lambing and the proportion of multiple births recorded $(\mathrm{R}=0.85)$.

The repeatability values for the number of lambs born per ewe at lambing are $0.04 \pm 0.02$ using the analysis of variance method; but 0.13 and 0.18 using the regression method between the first and subsequent lambings; and between the second and subsequent lambings respectively. The higher value obtained with the regression method agree with the results published by Young, Turner and Dolling (1963) on Australian Merinos and Forrest and Maurice (1974) on lowland sheep. For predicting future lambing performance, these workers are agreed that the regression method is particularly useful. According to Young et al (1963) the record at the second lambing is a better predictor of the futurc performance than the record at the first lambing. However, because of the low values obtained by either method, the improvement in the reproductive potential of the flock through selection would be small. The results in figure 3 show that the reproductive performance of the ewes increases with the age and the stage of lambing of the ewes, however Table $\mathrm{I}$ shows that whatever improvement one would get from selection for twinning and older ewes would be masked by the relatively poor performance of the younger ewes entering the flock.

Ewes born as twins appear to be more disadvantaged than the singles at the first 3 lambings.

The distribution of the sex of the lambs at birth was in the proportion of 49 males to $5 \mathrm{I}$ females. This agrees with the general values reported by other workers for sheep (Rae I956, Asdeli 1964). When the type of birth was considered, the proportion was unchanged for the singles but with the multiples the proportion was 48 males to 52 females. There was no significant monthly or seasonal influence on the sex of the lambs born.

In conclusion, this study has shown that there is plenty of room for improvement in the flock; the average ewe by the age of four years would have had at least 6 lambs, while the best and below average would have produced 10 and 3 lambs respectively. Because the repeatability values for these parameters are low, any anticipated improvement in the reproductive potential of the flock through selection would only bc modcrate. Besides, any gains following selection would be masked by the relatively poor performance of the ewes in their first few lambings. Proper management and general improvement in the environment of the flock would therefore play a greater role in the improvement of the flock reproductive performance.

TABLE 1

The relationship between an ewe's form of birth and her subsequent performance

\begin{tabular}{|c|c|c|c|c|}
\hline Eques born as & $\begin{array}{l}\text { Average number of lambs } \\
\text { I lambing: }\end{array}$ & $\begin{array}{l}\text { from the ewes } \\
\quad 2 \text { lambings: }\end{array}$ & $\begin{array}{l}\text { based on all ewes tho } \\
3 \text { lambings }\end{array}$ & $\begin{array}{l}\text { pleted at least:- } \\
4 \text { lambings: }\end{array}$ \\
\hline Singles & $\begin{array}{l}1 \cdot 397 \\
\left(15^{6}\right) \div\end{array}$ & $\begin{array}{l}\text { I } 4225 \\
(134)\end{array}$ & $\begin{array}{l}1 \cdot 54^{\mathrm{I}} \\
\left(9^{8}\right)^{-}\end{array}$ & $\begin{array}{l}I \cdot 4.3^{I} \\
(65)^{-}\end{array}$ \\
\hline 'lwins & $\begin{array}{l}1 \cdot 37^{6} \\
178)\end{array}$ & $\begin{array}{l}1 \cdot 407 \\
(150)\end{array}$ & $\begin{array}{l}1 \cdot 539 \\
(102)\end{array}$ & $\begin{array}{l}1 \cdot 646 \\
(65)\end{array}$ \\
\hline 'Triplets & $\begin{array}{l}1 \cdot 273 \\
(14)\end{array}$ & $\mathrm{r} \cdot 333$ & $\stackrel{1 \cdot 333}{(1)}$ & nil \\
\hline
\end{tabular}

+ Number in brackets represent the lambings used in the calculations. 


\section{ACKNOWLEDGEMENT}

We are grateful to the staff of the sheep unit of the Teaching and Research Farm, University of Ibadan for their assistance during the study. B.I.O. also wishes to thank the University of Nigeria, Nsukka for the Junior Fellowship which made this study possible.

\section{REFERENCES}

Asdelt, S. A. (1964). Patterns of mammalian reproduction. and ed. Constable \& Co. Ltd. condon.

Detremers, A. and Loosir, J. K. (1974). Live performance and carcass characteristics of the West African Dwarf sheep. Abstr. in Proc. Nig. Soc. An. Prod.

Donald, H. P., Read, J. L. Russell, W. S. (I968). A comparative trial of crossbred ewes by Finnish Landrace and other sired. Anim. Prod. Io: $413-42$ I.

Drxmundsson, O. R. (r973). Puberty and early reproductive performance in sheep. 1. Ewe lambs Anim. Breed. Abstr. 4x: 273-28g.

Forrest, P. A. and Maurice, B. (1974). Analysis of production records from I.owland sheep flock (3) Phenotypic and Genetic parameters for reproductive performance. Anim. Prod. r9: $33-45$.
Hill, D. H. (1960). West African Dwarf sheep. 3rd Annual Conf. Sci. Assoc. Nigeria.

Jones, D. N. (1959). Performance of Blackface sheep at Glensaugh Trans. Ro. Highl. Agric. Soc.; 6th Ser..3: 87-99.

Lush J. L. (1956). Querries, Biometrics 12: 84-88.

Orji, B. I. and Sterniach, J. (1976). Puberty in ewe I ambs of the Nigerian Dwarf sheep. Abstr. in Proc. 3rd Ann. Conf. Nig. Soc. Anim. Prod.

Rat, A. L. (1956). "The genetics of the sheep. Advances in Genetics, 3: $189-265$. New York, Academic Prcss.

Rendel, J. (I956). Heriability of multiple birth in sheep J. Anim. Sci. 15: 193-201.

TERrili., C. E. (Ig68). In Reproduction of sheep in Reproduction in Farm Animals; E. S. E. Hafex and ed. Lea \& Febiger Philadelphia.

Turner, H. N. and Young, S. S. Y. (1969). Quantitative Genetics in sheep Breeding. Cornell University Press, Ithaca, New York.

YaLCiN, B. Ci. and BichaRd, M. (I 964). Crossbred Sheep Production. 1. The repeatability of performance and scope for culling. Anim. Prod. 6: $85-90$.

Young, S. S. Y.; Turner, H. N.; Dolling, C. N. S. (1963). Selection for Fertility in Australian Merino sheep. Austr. J. Agric. Res. $44: 460-47^{8}$. 